\title{
Personal relevance of traits and things
}

\author{
JOHN H. MUELLER, STEVEN G. HAUPT, and TIMOTHY R. GROVE \\ University of Missouri, Columbia, Missouri
}

\begin{abstract}
Subjects made self- and other-descriptiveness decisions about various trait adjectives, as well as self- and other-possession decisions for a series of concrete nouns. The self-other difference was significant only for adjectives, and appeared for both decision speed and recognition. For adjectives, the self-other latency difference was more pronounced for individuals high in private self-consciousness, but there was no self-consciousness difference for noun latencies. Individual differences in need for cognition also moderated the self-other latency effect for adjectives, but not for nouns. Neither self-consciousness nor need for cognition significantly moderated self-other differences in recognition, but the two dimensions seemed to affect recognition in different ways.
\end{abstract}

Personal relevance has been shown to be an important determinant of memory for trait adjectives (e.g., Rogers, Kuiper, \& Kirker, 1977). For example, self-reference decisions are generally made faster and lead to better retention than decisions about semantic content (see Greenwald, 1981). These patterns are fairly common when the selfreferenced material consists of trait adjectives. Furthermore, similar benefits occur when the decisions involve familiar others (e.g., Bower \& Gilligan, 1979; Kuiper \& Rogers, 1979).

The self-reference benefit is less clear, however, when the material consists of something other than trait adjectives. For example, Keenan and Baillet (1980) used cities in self-reference decisions (e.g., "Does your city have streets?"'), and found that the self-reference benefit was unreliable. They concluded that the self-reference benefit would occur only when evaluation was involved, which tacitly occurs with trait adjectives, and not when factual judgments are being made. Maki and McCaul (1985) reported two related experiments, and obtained the selfreference benefit with adjectives but not with nouns in each case.

The present experiment was a further comparison of the differential effects of adjectives and nouns upon selfreference decisions. The procedure is somewhat like that employed by Maki and McCaul, but we used a recognition test of memory rather than free recall. Retrievability of self-related information has recently been discussed by Bellezza (e.g., 1987), and, to the extent that a recognition test may reduce this component relative to recall, it seems worth exploring in this context.

A second difference from Maki and McCaul (1985) is that we examined individual differences measures to determine whether the adjective-noun difference is dependent upon the subject's degree of self-awareness. The SelfConsciousness Questionnaire (Buss, 1980) has often been

The authors wish to acknowledge the assistance of John Vogel and Tammy Lamb. Requests for reprints should be sent to J. Mueller, Psychology Department, 210 McAlester Hall, University of Missouri, Columbia, MO 65211. employed in self-reference research, for which the hypothesis has been that individuals who are high in private self-consciousness (tendency to examine moods, motives, etc.) will have better access to personally relevant information, thereby accentuating the benefits of selfreferencing experiences (see Agatstein \& Buchanan, 1984). Although this is not always supported, such a pattern is often obtained with trait adjectives (e.g., Turner, 1980 ), and it seems reasonable to explore this issue with nouns as well.

In addition, for exploratory purposes, we included the Need for Cognition inventory developed by Cacioppo, Petty, and Kao (1984). This measure assesses an individual's tendency to engage in and enjoy cognitive processing. Although not specifically related to cognitions about the self, this inventory could be relevant, in that such a general measure may cover a person's knowledge of traits and things, rather than simply traits.

\section{METHOD}

\section{Subjects}

Seventy-one students (42 women, 29 men) from introductory psychology courses participated as subjects, in return for extra credit in their courses.

\section{Materials}

The items rated were 96 trait adjectives selected from the middle range of likability in the Anderson (1968) norms (e.g., agreeable, careful, efficient, hospitable, methodical, outgoing; with likability ratings between 4.40 and 1.43), and 96 common concrete nouns chosen from such sources as the Paivio, Yuille, and Madigan (1968) and Paivio (1973) norms (e.g., ankle, barrel, candle, comb, garden, ladder). Half of the items of each type were randomly designated as distractors for each subject, and the other half were later used as the "old" items during the rating phase of the recognition test.

\section{Procedure}

In the rating phase, the 48 adjectives and 48 nouns selected to be rated were randomly assigned so that half of each type were involved in selfreference decisions and half were other-reference targets. Thus, the subjects completed 24 statements of the type "I am (adjective)," 24 of the type "I have a (noun)," 24 of the type "Most people are (adjective)," and 24 of the type "Most people have a (noun)," in random order.

The materials were presented on a video monitor controlled by a microcomputer. The subjects responded by pressing keys to indicate either 
"yes" or "no." The subjects were instructed to respond quickly, on the basis of a rapid first impression. To encourage less inhibited responses, the experimenter was not present during this phase.

The rating phase was followed by a single-alternative recognition memory test. The 96 items ( 48 adjectives, 48 nouns) that had been rated were mixed with the other 96 items (48 adjectives, 48 nouns) and presented in random order. Each subject identified each item as "old" or "new" (previously rated or not), at a self-paced rate.

The next phase of the experiment was the Self-Consciousness Questionnaire (Buss, 1980), in which 23 items were presented one at a time on the monitor. The subjects answered on a 5-point scale by pressing a key. This inventory provides an estimate of private self-consciousness, public self-consciousness (monitoring of appearance to others), and social anxiety (arousal in the presence of others).

The final phase of the experiment was the Need for Cognition Scale (Cacioppo, Petty, \& Kao, 1984), in which 18 items were presented in a similar fashion.

\section{RESULTS}

The basic results are summarized in Table 1. The decision speeds and recognition hit rates were analyzed in an item (adjective, noun) $\times$ target (self, other) $\times$ decision ("yes," "no") layout, with all of the factors as within-subjects.

As expected, the latency data showed that the subjects made faster responses when the decision involved selfreference than when it involved other reference $[F(1,69)$ $=34.71, p<.0001 ; M s=1,440$ vs. $1,590 \mathrm{msec}]$, and decisions yielding a positive answer were made faster than those producing a negative judgment $[F(1,69)=29.15$, $p<.0001 ; M s=1,434$ vs. $1,595 \mathrm{msec}$. In addition, there was a main effect of item type $[F(1,69)=164.78$, $p<.0001$ ]; decisions that involved nouns were made faster than those that involved trait adjectives $(M s=1,226$ vs. $1,803 \mathrm{msec}$ ).

There were two interactions of note. First, the item $\times$ decision interaction $[F(1,69)=18.91, p<.0001]$ indicated that the difference between positive and negative judgments was present only for the trait adjectives (see Table 1). Second, the item type $\times$ target $\times$ decision interaction was significant $[F(1,69)=5.97, p<.02]$. As can be seen in Table 1, the self-reference benefit (faster decisions) for positive responses was limited to the adjectives, whereas the self-reference benefit for items yield-

Table 1

Average Decision Latencies (msec) and Recognition Hit Rates (\%), by Target, Type of Item, and Decision Result

\begin{tabular}{|c|c|c|c|c|}
\hline & \multicolumn{2}{|c|}{ Adjectives } & \multicolumn{2}{|c|}{ Nouns } \\
\hline & Self & Other & Self & Other \\
\hline \multicolumn{5}{|c|}{ Latencies } \\
\hline $\begin{array}{l}\text { Yes Decisions } \\
\text { No Decisions }\end{array}$ & $\begin{array}{l}1529 \\
1904\end{array}$ & $\begin{array}{l}1803 \\
1978\end{array}$ & $\begin{array}{l}1145 \\
1180\end{array}$ & $\begin{array}{l}1260 \\
1319\end{array}$ \\
\hline \multicolumn{5}{|c|}{ Hit Rates } \\
\hline $\begin{array}{l}\text { Yes Decisions } \\
\text { No Decisions }\end{array}$ & $\begin{array}{l}93.1 \\
90.0\end{array}$ & $\begin{array}{l}89.5 \\
86.1\end{array}$ & $\begin{array}{l}92.2 \\
92.2\end{array}$ & $\begin{array}{l}91.3 \\
92.7\end{array}$ \\
\hline
\end{tabular}

Table 2

Correlations Between Self-Consciousness Questionnaire Subscales, Need for Cognition Scores, Decision Latencies, and Hit Rates

Social Need for Private Public Anxiety Cognition

Latencies

$\begin{array}{lrrrr}\text { Adjective, Self-Positive } & -.19 & .04 & .06 & -.23 * \\ \text { Adjective, Other-Positive } & .07 & .05 & .03 & -.03 \\ \text { Noun, Self-Positive } & -.14 & -.01 & -.03 & .07 \\ \text { Noun, Other-Positive } & .04 & -.01 & -.05 & .15\end{array}$

Hit Rates

\begin{tabular}{lrrrc} 
Adjective, Self-Positive & -.19 & -.16 & .13 & .17 \\
Adjective, Other-Positive & .01 & -.10 & -.14 & $.25 *$ \\
Noun, Self-Positive & -.03 & .03 & .04 & .05 \\
Noun, Other-Positive & .01 & .10 & -.02 & -.01 \\
\hline Note-n=71. ${ }^{*} p<.05$ & & & &
\end{tabular}

ing a negative judgment was absent for the trait adjectives and nonsignificant for the nouns.

The recognition data showed better overall retention of the items involved in self-reference decisions $[F(1,69)$ $=7.38, p<.01$ ], but there was an item $\times$ target interaction qualifying this effect $[F(1,69)=6.76, p<.01]$, as the self-reference benefit was present for trait adjectives but not apparent for the nouns. There was also an item $\times$ decision interaction $[F(1,69)=7.41, p<.01]$, as items that led to a "yes" response were better remembered than those leading to a "no" response when the target was the self, but there was no difference for positive and negative judgments when the target was other people. There were no other significant effects in the basic recognition data.

The data from the Self-Consciousness Questionnaire were analyzed in two ways. First, we computed correlations between the scores on the private self-consciousness subscale and the decision speeds and hit rates. As can be seen in Table 2, none of these correlations was statistically significant. There was a nonsignificant tendency for individuals high in private self-consciousness to make faster decisions on both adjectives and nouns $(p s<.12)$, and a similar nonsignificant tendency for subjects to show worse recognition $(p<.12)$. Furthermore, selfconsciousness was uncorrelated with false alarm rates for either adjectives or nouns $[r s(71)=-.02$ and .11].

Second, the subjects were ranked on private selfconsciousness scores and divided at the median (34.5). Private self-consciousness was then added to the design indicated above as a two-level between-subjects factor. This reanalysis of the latency data indicated only one interaction between private self-consciousness and any other factor - the triple interaction of self-consciousness $\times$ item $\times$ target $[F(1,69)=8.81, p<.01]$. The difference between individuals high and those low in self-consciousness was significant for adjectives involved in self-reference decisions $(M s=1,592$ vs. $1,825 \mathrm{msec})$, but not for adjectives involved in other-reference decisions $(M s=1,870$ 
Table 3

Correlations Between the Self-Consciousness Questionnaire Subscales and Need for Cognition

\begin{tabular}{lccc}
\hline & Public & $\begin{array}{c}\text { Social } \\
\text { Anxiety }\end{array}$ & $\begin{array}{c}\text { Need for } \\
\text { Cognition }\end{array}$ \\
\hline Private Self-Consciousness & $.35^{*}$ & -.02 & .22 \\
Public Self-Consciousness & & .19 & -.15 \\
Social Anxiety & & & -.16 \\
\hline
\end{tabular}

Note $-N=71 .{ }^{*} p<.05$.

vs. $1,907 \mathrm{msec}$ ), nouns involved in self-reference decisions $(M \mathrm{~s}=1,171 \mathrm{vs} .1,156 \mathrm{msec})$, or nouns involved in other-reference decisions $(M \mathrm{~s}=1,267 \mathrm{vs}$. $1,309 \mathrm{msec}$ ).

The inclusion of private self-consciousness as a factor in the reanalysis of the recognition data revealed no interactions with any of the other factors.

The Need for Cognition scores were also correlated with decision speed and hit rates, as well as with the subscales of the Self-Consciousness Questionnaire. Table 2 shows that individuals with high need for cognition made significantly faster decisions for self-reference adjectives but not for self-reference nouns. In addition, subjects with high need for cognition showed better recognition for trait adjectives but not for nouns.

The subjects were divided at the median (60.5) on Need for Cognition scores. We then added need for cognition as a two-level factor in the design indicated above, but this reanalysis of the latencies and hit rates served only to corroborate the results indicated in Table 2 .

The recognition data indicate that need for cognition and private self-consciousness had opposing effects on retention, although neither had a statistically significant effect by itself; that is, the correlations that involved the recall of adjectives and those that involved positive self-reference decisions were significantly different from one another, although neither was significantly different from zero $(r s=-.19$ vs. $.17, p<.02)$. This outcome indicates that the two dimensions involve somewhat different processes, and that need for cognition has a more general positive effect on retention, at least for adjectives.

To assess the issue of independence of the personality dimensions, the scores from the two questionnaires were correlated (see Table 3). As can be seen, need for cognition did not correlate significantly with any of the selfconsciousness subscales, although the correlation with private self-consciousness was just short of the minimal level of significance $(p<.07)$. Mueller and Johnson (1987) also failed to observe a significant correlation between private self-consciousness and need for cognition.

\section{DISCUSSION}

The present results clearly indicate that the self-reference advantage was greater for trait adjectives than for nouns. This "benefit" was indexed by faster self-descriptiveness decisions relative to other- descriptiveness decisions, and better recognition of self-referenced material. The noun reference statement here was worded slightly differently from that used by Maki and McCaul (1985; i.e., "I have a _-" as opposed to "I use a _-"), and the present retention test was recognition rather than recall, but the outcome was quite similar, with no apparent self-reference benefits for nouns.

The inclusion of individual differences data here indicates that the absence of the self-reference effect for nouns was not connected in any obvious way to measures of self-awareness or cognitive activity. The private self-consciousness subscale of the Buss (1980) Self-Consciousness Questionnaire indicated no significant association with speed of access or retention, regardless of target (self or other) or material (adjective or noun). The index of more general cognitive activity, or need for cognition, was correlated with speed of access and retention of adjectives, but was not related to measures involving noun decisions. Although this is of interest, it does not indicate that subjects with higher need for cognition would begin to show self-reference benefits for nouns.

This positive correlation between need for cognition and recall of positively self-referenced items was also observed by Mueller and Johnson (1987), who also replicated the nonsignificant negative correlation between private self-consciousness and recall. Although their procedure was quite different, Srull, Lichtenstein, and Rothbart (1985, Experiment 2) likewise found that high need for cognition was associated with greater recall of congruent information about people, analogous to the "yes" decisions here. Srull et al. actually found the greatest impact of need for cognition on incongruent instances, with no effect on irrelevant information. The present data indicate no correlations between need for cognition and either latency or recognition of items involved in "no" decisions, for either adjectives or nouns, for either self or other, but because of procedural differences it is not clear whether negative decisions here should be construed as analogous to irrelevant or incongruent information in the Srull et al. format. In any event, however, high need for cognition did yield better retention both here and elsewhere, and seems a promising individual differences variable for consideration in future work of this type.

\section{REFERENCES}

Agatstein, F. C., \& Buchanan, D. B. (1984). Public and private selfconsciousness and the recall of self-relevant information. Personality \& Social Psychology Bulletin, 10, 314-325.

ANDERSON, N. H. (1968). Likableness ratings of 555 personality-trait words. Journal of Personality \& Social Psychology, 9, 272-279.

BellezzA, F. S. (1987). Reliability of retrieving information from knowledge structures in memory: Self information. Bulletin of the Psychonomic Society, 25, 407-410.

Bower, G. H., \& Giluigan, S. G. (1979). Remembering information about one's self. Journal of Research in Personality, 13, 420-432.

Buss, A. H. (1980). Self consciousness and social anxiety. San Francisco: W. H. Freeman.

Cacioppo, J. T., Petty, R. E., \& Kao, C. F. (1984). The efficient assessment of need for cognition. Journal of Personality Assessment, 48, 306-307.

GreENWALD, A. G. (1981). Self and memory. In G. H. Bower (Ed.), Psychology of learning and motivation (Vol. 15, pp. 201-236). New York: Academic Press.

Keenan, J. M., \& Baillet, S. D. (1980). Memory for personally and socially significant events. In R. S. Nickerson (Ed.), Attention and performance (Vol. 8, pp. 651-669). Hillsdale, NJ: Erlbaum.

KUIPER, N. A., \& Rogers, T. B. (1979). Encoding of personal information: Self-other differences. Journal of Personality \& Social Psychology, 37, 499-514.

MAKI, R. H., \& MCCAUL, K. D. (1985). The effects of self-reference versus other-reference on the recall of traits and nouns. Bulletin of the Psychonomic Society, 23, 169-172.

Mueller, J. H., \& JohNSON, W. C. (1987, May). Trait distinctiveness and age specificity in self-referent information processing. Paper presented at the Annual Meeting of the Midwestern Psychological Association, Chicago. 
Rogers, T. B., KUIPER, N. A., \& KIRKER, W. S. (1977). Self-reference and the encoding of personal information. Journal of Personality \& Social Psychology, 35, 677-688.

PaIvio, A. (1973). Imagery and familiarity ratings for 2448 words. Unpublished norms, University of Western Ontario, Department of Psychology, London, Ontario, Canada.

Paivio, A., Yuille, J. C., Madigan, S. A. (1968). Concreteness, imagery, and meaningfulness values for 925 nouns. Journal of Experimental Psychology Monograph Supplement, 76 (1, Pt. 2).
Srull, T. K., Lichtenstein, M., \& Rothbart, M. (1985). Associative storage and retrieval processes in person memory. Journal of Experimental Psychology: Learning, Memory, \& Cognition, 11, 316-345.

TURNER, R. G. (1980). Self-consciousness and memory of trait terms. Personality \& Social Psychology Bulletin, 6, 273-277.

(Manuscript received for publication March 8, 1988.) 